\title{
Experimental aluminium encephalopathy: quantitative EEG analysis of aluminium bioavailability
}

\author{
C CUTRUFO, S CAROLI, P DELLE FEMMINE, E ORTOLANI, S PALAZZESI, \\ N VIOLANTE, GA ZAPPONI, A LOIZZO
}

From the Istituto Superiore di Sanità, Rome, Italy

SUMMARY Single oral doses of aluminium hydroxide (50 to $200 \mathrm{mg} / \mathrm{kg}$ ) were found to induce in mice a dose-dependent diminution of the power of the 7.5 to $12 \mathrm{~Hz}$ frequency band, with a parallel dose-dependent increase of aluminium content in the brain, as early as 45 min after administration, and indicated that aluminium hydroxide is readily absorbed through an empty stomach or duodenum and is able to induce alterations of background EEG rhythms at doses equivalent to the ones used in human therapy. These data suggest that the EEG disturbances of the background type, (which are observed during the early stage of dialysis encephalopathy in man), may be partly due to a pharmacological and therefore reversible effect induced by an increase in aluminium level in the brain.

Electroencephalographic (EEG) findings in dialysis encephalopathy have been extensively described, ${ }^{1-5}$ as well as EEG with behaviour patterns induced by aluminium intoxication, which in part have been reproduced in animal subjects. ${ }^{6-10}$ Both human electrophysiological studies and experiments on animals point to the existence of two main alterations: in early stages slowing and disturbances of background rhythms (in human studies) or disturbances of neuron discharges or of evoked responses (in animal studies) ensue. Following advanced intoxication, epileptiform abnormalities also appear, both in man and animals. The aim of this study was to verify: (1) whether EEG alterations could be detected in animals at a very early stage of aluminium intoxication, with the aid of computerized techniques, and, if so, (2) whether the two EEG alterations, of the background and of the epileptiform type, could be related to patho-physiological models different to morphological neuron alterations models.

Address for reprint requests: Dr A Loizzo, Istituto Superiore di Sanità, Viale Regina Elena, 299, 00161 Roma, Italy.

Received 9 January 1983 and in final revised form 14 August 1983. Accepted 14 September 1983

\section{Methods}

Sixteen DBA/2 male mice weighing 24-28 g were chronically implanted with four epidural monopolar electrodes positioned on the sensorimotor cortex." One week after surgery the EEG of the subjects which had fasted for 24 hours was recorded on paper and on magnetic tape according to the following experimental schedule: $60 \mathrm{~min}$ before treatment, the EEG was recorded at intervals of $15 \mathrm{~min}$ for 2-3 min, while acoustic stimulation of $90 \pm 2 \mathrm{~dB}$ was given. After this period drug or saline were given by mouth, four animals for each dose, then EEG was recorded for 90 more min, using the same procedure. Administered doses in this study were 50,100 and $200 \mathrm{mg} / \mathrm{kg}$ of a commercially available aluminium hydroxide powder in $0.2 \mathrm{ml}$ saline. Artifact-free EEG samples were fed to a minicomputer off-line and band-pass filtered between 0.5 and $45 \mathrm{~Hz}$. Power spectra were built up from 0 to $64 \mathrm{~Hz}$, with steps of $0.5 \mathrm{~Hz}$ (lines) using standard FFT algorhythm, and stored on digital tapes. Frequency bands were built by cumulating power values of adjacent lines showing high intercorrelation, according to previously described techniques; ${ }^{12}$ mean spectra were then computed over six frequency bands $(0.5$ to $3.5 ; 4$ to $7 ; 7.5$ to $12 ; 12.5$ to $16 ; 16.5$ to 20 and 20.5 to $40 \mathrm{~Hz}$ ), for each period of 2-3 min duration, for the anterior-posterior left sensorimotor cortex. EEG data, expressed as per cent of pre-drug in each animal, were analysed statistically using parametric procedures: twoways analysis of variance, with the test for linearity of regression of the means. ${ }^{13}$ 
Analytical procedure. Twenty mice were divided into four groups at random. After 24 hours fasting, animals were given saline or aluminium hydroxide by intragastric tube, in doses and conditions similar to those used for the EEG experiments. Animals were sacrificed $45 \mathrm{~min}$ after drug administration, the brains were removed and kept frozen until analysis began.

Chemical analysis was performed according to previously described procedures. ${ }^{14}$ is Organs were wet-ashed in concentrated nitric acid, and evaporation was stopped when the final volume of solution was about $2 \mathrm{ml}$. The solution was subsequently diluted to a volume of $10 \mathrm{ml}$ with doubly-distilled water, and three identical aliquots of each were sampled in order to analyse their aluminium content using atomic absorption spectrometry (AAS). Contamination of the samples was minimised by adopting strict procedure controls. For each series of measurements however, blank determinations were also made and taken into account in the final calculations whenever necessary. Data obtained from chemical procedures were evaluated using one-way analysis of variance and regression analysis. $^{16}$

\section{Results}

EEG and necropsy data. Following saline or low doses of the drug no modification in frequency and voltage of EEG waves was noted in mice. About 20 to $30 \mathrm{~min}$ after $200 \mathrm{mg} / \mathrm{kg}$ a slight diminution of voltage lasting up to $30 \mathrm{~min}$ was visible while wave morphology remained unchanged. No gross alteration of spontaneous motor activity was noticed at all, and no EEG epileptiform alterations were ever shown. On dissection, complete or almost complete emptiness of the stomach and duodenum was checked.

Computer EEG data. Fifteen to $20 \mathrm{~min}$ after the lowest dose of aluminium hydroxide a transitory but not consistent depression of EEG in the $7 \cdot 5$ to $12 \mathrm{~Hz}$ frequency band occurred in mice. After 100 and $200 \mathrm{mg} / \mathrm{kg}$ a relevant drop in power of the same frequency band was noted lasting up to $20-40 \mathrm{~min}$. This diminution, computed as a mean of the four animals per dose in the five EEG recording periods of 2 min duration $(15,30,45,60$ and 75 min after drug) was significantly dose related $(F=49.86$; $\mathrm{p}<0.001$ ) (table). No consistent effects were seen in the other band power values.

Chemical analysis data. Forty five min after dosing, brain aluminium content in treated mice was higher than in controls, in a relevant dose-related manner. $(\gamma=95 \cdot 1+0.96 x ; r=0.85 ; \rho<0.001)$

\section{Discussion}

Brain aluminium content rose remarkably in a dose-dependent manner in mice after aluminium
Table Two-way analysis of variance and regression analysis of effects induced by aluminium hydroxide on the EEG of mice

\begin{tabular}{|c|c|c|c|c|}
\hline Variation source & Sum of squares & $d F$ & Mean squares & $F$ \\
\hline \multirow{4}{*}{$\begin{array}{l}\text { Treatment } \\
\text { (Linear regression) } \\
\text { (Deviations from } \\
\text { regression) } \\
\text { Error } \\
\text { Total }\end{array}$} & $\begin{array}{c}2054 \cdot 51 \\
(1875 \cdot 84)\end{array}$ & $\begin{array}{r}3 \\
(1)\end{array}$ & $\begin{array}{c}648 \cdot 8 \\
(1875 \cdot 84)\end{array}$ & $\begin{array}{c}18 \cdot 2^{*} \\
(49 \cdot 86)^{*}\end{array}$ \\
\hline & $(178 \cdot 66)$ & (2) & $(89 \cdot 33)$ & $(2 \cdot 37)(\mathrm{ns})$ \\
\hline & $601 \cdot 88$ & 16 & 37.62 & \\
\hline & $2656 \cdot 39$ & 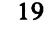 & & \\
\hline
\end{tabular}

Regression curve: y $100 \cdot 1-0 \cdot 13$ x

${ }^{*} \mathrm{p}<0.001$

ns not significant

The three doses of aluminium hydroxide induced a dose-dependent depression on the power of 7.5 to $12 \mathrm{c} / \mathrm{s}$ frequency band of sensorimotor cortex in mice. Regression analysis of effects has been computed on the values of relative power (per cent of total power in pre-drug EEG, as a mean of 4 animals per dose) in the fve EEG recording periods of 2 min duration, on the basis of two-ways analysis of variance. Note that $F$ values for treatment and for linear regression are highly significant, while no consistent deviation from linear regression is evident.

hydroxide administration, and the increase was related to the EEG effect. Previous data from Berlyne $e t$ al ${ }^{8}$ suggested that chronically administered aluminium hydroxide in rats resulted in an enhanced aluminium content in various tissues, including brain. Bowdler et al, ${ }^{6}$ found significant correlations between serum or brain aluminium levels and administered dose, between serum and brain aluminium levels, between brain levels and administered dose in rats chronically treated with various aluminium salts per os, in doses varying between 17 and $180 \mathrm{mg} / \mathrm{kg}$ as elemental aluminium. Moreover Kaehny et al ${ }^{17}$ found an increase of 2-3 times of plasma aluminium level after dosing human volunteers with $2.2 \mathrm{~g}$ aluminium hydroxide/day per os, that is about $50 \mathrm{mg} / \mathrm{kg}$ per day, given in divided doses between meals. This dose as drug weight per $\mathrm{kg}$ body weight, corresponds approximately to the dose administered in our experiments. Therefore our findings indicate that aluminium, even with a therapeutic dosage, brings about a measurable effect on brain electrogenesis. This datum must be viewed with caution, since it would imply that there is massive absorption in the acid milieu of the stomach or in the proximal tract of the small intestine within 30-60 min after gavage and that aluminium ions may cross the blood-brain barrier. Nevertheless, in our experimental conditions brain aluminium content was consistently higher in treated mice $45 \mathrm{~min}$ after dosing. Therefore chemical data suggest that EEG alterations are induced at least in part by aluminium absorption and not merely by some neurohumoral reflex mechanisms triggered through the chemo-physical properties of aluminium hydroxide in the stomach or duodenum of experimental animals. 
Quantitative EEG analysis also suggests that in animals electrophysiological changes become evident when aluminium brain content is raised by 2 to 3 times the normal values, 30 to $60 \mathrm{~min}$ after a single administration, that is when morphological neuron changes have not occurred. Our data therefore strongly support, with EEG and chemical evidence, the possibility that a metabolic effect of minute doses of aluminium is exerted upon neurons which do not develop neurofibrillary degeneration in animal models, as was suggested by Crapper and Tomko. ${ }^{18}$

Sanderson et al ${ }^{19}$ moreover, showed that the mean binding of corticosterone decreased by $25 \%$ in hippocampal cell nuclei from aluminium treated rabbits, suggesting thus a possible functional consequence of the presence of aluminium in the limbic system, in the absence of morphologic changes; and it is well known that there exists a strict correlation between high voltage slow hippocampal EEG rhythm, and the 6 to $12 \mathrm{~Hz}$ rhythm which is recorded in the sensorimotor cortex of small mammals. ${ }^{20-22}$

Therefore EEG data obtained in our laboratory support the hypothesis that the limbic system is implied in the physio-pharmacologic mechanisms underlying the action of aluminium on brain electrical activity in animals. ${ }^{23}$ Although extrapolation of animal data to humans is often questionable, it is reasonable to think that the slowing of background EEG activity observed in dialysis encephalopathy patients may be due in part to a pharmacological effect exerted by aluminium ions, while EEG alterations of the epileptiform type ${ }^{3}$ seem to occur when also massive neuron damage can be seen, that is, during an advanced stage of intoxication.

The authors thank the Servizio di Documentazione Bibliografica of ISS and Mrs G Tognoli for help in bibliographic research.

\section{References}

${ }^{1}$ Chokroverty S, Bruetman ME, Berger V, Reyes MG. Progressive dialytic encephalopathy. $J$ Neurol Neurosurg Psychiatry 1976;39:411-9.

${ }^{2}$ Nadel AM, Wilson WP. Dialysis encephalopathy: A possible seizure disorder. Neurology (Minneap) 1976;26:1130-4.

${ }^{3}$ Vecchierini-Blineau MF, Thebaud HE, Dupovet L, et al. Etude chronologique des signes de l'encéphalopathie myoclonique des hémodialysée. Sem Hôp Paris 1981;57:1823-30.

${ }^{4}$ Chokroverty S, Gandhl V. Electroencephalograms in patients with progressive dialytic encephalopathy. Clin EEG 1982;13:122-127.

s Hughes JR, Schreeder MT. EEG in dialysis encephalopathy. Neurology (Minneap) 1980;30: 1148-54.
${ }^{6}$ Bowdler NC, Beasley DS, Fritze EC, et al. Behavioral effects of aluminium ingestion on animal and human subjects. Pharm Biochem Behav 1979;10:505-12.

${ }^{7}$ Klatzo I, Wisniewski H, Streicher E. Experimental production of neurofibrillary degeneration I. Light microscopic observations. Neuropath Exp Neurol 1965;24:187-99.

${ }^{8}$ Berlyne GM, Ben Ari J, Knopf E, Yagil R, Weinberger G, Danivitch GM. Aluminium toxicity in rats. Lancet 1972;1:564-8.

${ }^{9}$ Crapper DR, Dalton AJ. Aluminium induced neurofibrillary degeneration, brain electrical activity and alteration in acquisition and retention. Physiol Behav 1973;10:935-45.

${ }^{10}$ Crapper DR. Experimental neurofibrillary degeneration and altered electrical activity. Electroencephalogr Clin Neurophysiol 1973;35:575-88.

"Loizzo A. Correlati EEG dell'azione di alcuni farmaci psicotropi sul topo liberc non anestetizzato. EEG e comportamento nel topo trattato con farmaci anticolinergici. Studi Sassaresi 1969;47 (suppl.):72-91.

12 Zapponi GA, Lindsey CJ, Loizzo A. Electroencephalographic analysis of subacute effects of methyl-parathion in the mouse. In: Otto DA, ed. Multidisciplinary Prospectives in Event-Related Potential Research. U.S. Environmental Protection Agency - 600/9-77-043 Washington, DC, 1978.

${ }^{13}$ Edwards AL. Statistical Methods for the Behavioral Sciences. New York: Holt, Rinehart and Winston, 1964.

${ }^{14}$ Caroli S, Delle Femmine P, Alimonti A, Petrucci F, Violante N. Applicability of spectroscopic methods to the determination of aluminium in biological samples. Spectrosc Lett 1982;15:303-12.

${ }^{15}$ Caroli S, Senofonte O, Delle Femmine P. Determination of trace elements in biological materials using a hollow-cathode discharge: comparative study of matrix effects. Analyst 1983;108:196-203.

${ }^{16}$ Lison L. Statistica Applicata alla Biologia Sperimentale. Milano: Casa Editrice Ambrosiana, 1961.

${ }^{17}$ Kaehny WD, Heeg AP, Alfrey AC. Gastrointestinal absorption of aluminium from aluminium-containing antacids. $N$ Engl J Med 1977;296:1389-90.

${ }^{18}$ Crapper DJ, Tomko GT. Neuronal correlates of an encephalopathy associated with aluminium neurofibrillary degeneration. Brain Res 1975;97:253-64.

${ }^{19}$ Sanderson CL, Crapper McLachlan DR, De Boni U. Inhibition of corticosterone binding in vitro, in rabbit hippocampus, by chromatin bound aluminium. Acta Neuropathol (Berl.) 1982;57:249-54.

${ }^{20}$ Green JD, Arduini A. Hippocampal electrical activity in arousal. J Neurophysiol 1954;17:533-57.

${ }^{21}$ Green JD. The hippocampus. Physiol Rev 1964;44: 561-608.

${ }^{22}$ Vanderwolf $\mathrm{CH}$. Hippocampal electrical activity and voluntary movement in the rat. Electroencephalogr Clin Neurophysiol 1969;26:407-18.

${ }^{23}$ Farnell BJ, De Boni U, Crapper McLachlan DR. Aluminium neurotoxicity in the absence of neurofibrillary degeneration in C A 1 hippocampal pyramidal neuron in vitro. Exp Neurol 1982;78:24158. 